
\title{
$\begin{array}{ll}\text { Research Square } & \begin{array}{l}\text { Preprints are preliminary reports that have not undergone peer review. } \\ \text { They should not be considered conclusive, used to inform clinical practice, } \\ \text { or referenced by the media as validated information. }\end{array}\end{array}$
}

\section{What's That Bug? Citizen Science For Biosecurity In Mount Maunganui, New Zealand}

\section{Penny Raewi Payne ( $\sim$ Penny.Payne@agresearch.co.nz )}

AgResearch Ltd Ruakura Research Centre https://orcid.org/0000-0001-8215-1643

\section{Susanna Finlay-Smits}

AgResearch Ltd Lincoln Research Centre

\section{Bruce Small}

AgResearch Ltd Ruakura Research Centre

Vanessa Cave

AgResearch Ltd Ruakura Research Centre

John Kean

AgResearch Ltd Ruakura Research Centre

\section{Research Article}

Keywords: Biosecurity, citizen science, education, New Zealand

Posted Date: August 13th, 2021

DOI: https://doi.org/10.21203/rs.3.rs-746797/v1

License: (c) (i) This work is licensed under a Creative Commons Attribution 4.0 International License. Read Full License 


\section{Abstract}

\section{Measuring biosecurity perceptions, awareness and behaviour: A New Zealand case study}

Tauranga Moana has been named the 'biosecurity capital' of New Zealand, as part of the government's 'Biosecurity $2025^{\prime}$ Initiative to enlist all New Zealanders as biosecurity risk managers. This will involve large-scale citizen science, for reporting, eradication and management of pest and disease threats. We measure baseline awareness, perceptions and behaviour about biosecurity among two key citizen science groups, the local community at Mount Maunganui (surrounding Tauranga's port) and school children. An online survey was completed by 324 members of the local community, while 120 school children completed a survey about their biosecurity knowledge and behaviours after using a biosecurity education kit. Results indicate that while both groups report a relatively high level of understanding about the concept of biosecurity, and acknowledge it as extremely important, knowledge of current pest threats and correct biosecurity behaviours could be improved. Mount Maunganui community members rate their understanding of biosecurity as better than the average New Zealander, but are less likely to have taken regular biosecurity action in the past year. For school children, improved biosecurity efforts could be evidenced by more active pest monitoring, and greater discussion about biosecurity outside of school (e.g. with their family at home). Key enablers for achieving more impactful citizen science for biosecurity among these groups are targeted education, and practical advice about what they can do to help.

\section{Introduction}

Biosecurity is a critical issue for New Zealand, which has unique native flora and fauna to protect, and many channels through which breaches could occur (Ministry for Primary Industries 2016). Recent high-profile biosecurity outbreaks in New Zealand include Mycoplasma bovis[1], myrtle rust[2], and kauri dieback disease[3] (MPI 2018a; du Plessis, Granados \& Barnes 2019; Smith 2017, respectively). These diseases represent a particularly difficult biosecurity challenge because common vectors for spreading the diseases relate to human behaviour. For example, allowing contact between infected cattle spreads $M$. bovis, touching or moving myrtle rust causes spores to spread to other plants, and hiking in the bush can spread kauri dieback spores (MPI 2018b; MPI 2018c; Smith 2017). This means it is critical to involve people, including the public, in detection, management and eradication of biosecurity threats, if management efforts are to be successful (Thomas et al. 2017). Involving citizens in biosecurity management is also a useful cost-saving strategy, albeit potentially risky if not effective (Campbell, Bryant \& Hewitt 2017).

One useful mechanism for involving the public in biosecurity is through citizen science projects. The use of citizen science is increasing, and the international literature has shown that it can be an effective mechanism for achieving biosecurity outcomes (Tulloch et al. 2013). For example, the public can assist with early detection through biosecurity surveillance programmes (e.g. Thomas et al. 2017), mapping the distribution of invasive species (e.g. Gallo \& Waitt 2011), and trapping and handling pests (Newman, Buesching \& Macdonald 2003). Moreover, although some members of the public may have little awareness and knowledge of biosecurity, they may still be concerned about biosecurity and be willing to implement biosecurity-related behaviours (Urquhart et al. 2017). New Zealand's 'Biosecurity 2025' initiative aims to do just this - use the entire population as a national biosecurity risk management force (Ministry for Primary Industries 2016). This 'team' involves both adults and children and will require a large scale and concerted effort to achieve engagement and informed reporting of biosecurity threats.

We present the findings of two studies measuring awareness, perceptions, knowledge and behaviours about biosecurity in a community living adjacent to New Zealand's busiest seaport. We surveyed both adults (Study 1), and primary school children (Study 2). The adult community survey serves as a baseline measure, which is compared with a national survey of biosecurity awareness and behaviours, as measured by Colmar Brunton (2018). The school

Page 2/23 
children survey is a longitudinal evaluation of a biosecurity education kit, administered before, immediately after, and six months after using the resource. This research is from a five-year project (to be completed in 2022), with this paper serving to report early results.

\section{Introduction}

The New Zealand public has proved their potential value as a biosecurity risk management force in terms of postborder passive surveillance, reporting $96 \%$ of the total reported pest and disease threats for the period 2005-2008 (Froud et al. 2008). Further, 18\% of New Zealanders report having taken regular action to control plant or animal pests somewhere beyond their own property, over the past year (Colmar Brunton 2018). These results suggest a significant degree of concern about biosecurity threats, and a willingness to help, across the New Zealand public. Despite positive intentions however, it appears that the public need further education; reports of new exotic organisms were correct only two percent of the time (Froud et al. 2008), suggesting a need to improve public familiarity with, and recognition of, current pest and diseases. Indeed, while $61 \%$ of New Zealanders say they have a good understanding of biosecurity and think it is important, only $29 \%$ agree they can identifythe main pests, weeds, and diseases that pose a threat to New Zealand wildlife and the environment (Colmar Brunton 2018).

The survey results reported in this paper represent the baseline data for benchmarking awareness, perceptions, knowledge, and behaviours of biosecurity using a sample from Mount Manganui, the coastal community adjacent to the Port of Tauranga (PoT). This area was chosen as it has been named the 'Biosecurity Capital of New Zealand', and it is anticipated that there will be interventions to raise awareness and reporting among the local community. Moreover, these residents live in the immediate vicinity of New Zealand's largest and fastest growing seaport (Port of Tauranga 2017). This therefore makes the public in this area critical 'eyes and ears' for incoming pest and disease threats.

The New Zealand government has also made it clear that children are expected to be involved in biosecurity risk management (Ministry for Primary Industries 2016). Examples in the literature suggest that involving children in citizen science projects can serve to do more than just increase awareness and promote positive biosecurity behaviours. Involvement may also promote a general appreciation of the local environment and enhance place-based identity (Evans et al. 2005). In adults, enhanced place-based identity has been found to be related to higher awareness and concern about biosecurity, so this may be a cyclical relationship which could be promoted at a younger age (Urquhart et al. 2017).

Biosecurity was also identified as a key area for inclusion in the school curriculum by Australian and New Zealand biosecurity groups (Department of Agriculture and Water Resources 2018). This is likely due to the increasing number of biosecurity concerns facing New Zealand and Australia, and the research suggesting children and younger people have a gap in knowledge about, and appreciation of, biosecurity. A study of New Zealand school students (approximately age 12) found that children had poor knowledge of biosecurity, including unwanted plants, organisms, and diseases (Ram et al. 2015). Another study found that younger people (under 30) were less likely to understand biosecurity, think it was important, or have awareness of the elements of the biosecurity system (Colmar Brunton 2018). New Zealanders under 24 were also found to be less confident about knowing what to do if they found an unwanted pest, weed, or disease, to do their own research, or to take direct action in controlling pests and weeds in and beyond their communities (Colmar Brunton 2018). Together, these factors suggest a need for improved education of children and young adults in New Zealand about biosecurity, and an opportunity for children to represent a long-term, intergenerational strategy for promoting biosecurity among New Zealand citizens.

The method, results and discussion will be presented for each study below, followed by a summary of what this means for biosecurity education efforts in New Zealand, and more broadly. 
[1] Mycoplasma bovis is a bacterium causing a range of serious conditions in cattle and other animals.

[2] Myrtle rust is a serious fungal disease, caused by Austropuccinia psidii, that affects plants in the myrtle family, including iconic New Zealand trees such as pōhutukawa, mānuka and rātā.

[3] Kauri dieback disease is caused by the pathogen Phytophthora agathidicida, which kills most kauri (a native New Zealand tree) it infects.

\section{Study 1: Local Community}

\section{Method}

The local community survey included Mount Maunganui residents from the immediate vicinity of the PoT[1]. The local community are the critical 'second line of defence', after port workers, given their proximity to the port. That is, if a biosecurity incursion were to occur just outside of the port, they may be the first people to notice, such as if a new insect became established in their garden. It is therefore critical that they are able to recognise foreign or unwanted pests and diseases and report them to authorities. At the time of our survey in early 2018, the local Mount Maunganui community had not been exposed to any direct awareness-raising interventions through the Port of Tauranga aside from Biosecurity Week in 2017, where attendance was low. Their awareness of biosecurity was most likely to have derived from broadly targeted interventions such as nationally aired television advertisements[2].

The focus of this survey was to measure baseline awareness about biosecurity, including key pest and/or disease threats, and perceptions and understanding of biosecurity. Performance of, or willingness to perform, biosecurity behaviours was also a key area of interest.

\section{Measurement tool}

An online survey was used to measure the local community's awareness of, perceptions about, and behaviours related to, biosecurity. The survey was mostly comprised of questions taken from the Colmar Brunton (2018) nationwide survey of New Zealand public about biosecurity (these questions are marked with a * in Table 1 below). Adding these questions served to provide a benchmark for comparison between the local Mount Maunganui community and the New Zealand adult community more broadly.

The survey included 23 questions in total, 13 of which directly related to biosecurity, and six of which were demographic questions. Participants were asked to provide self-assessments of their understanding, knowledge, perceptions and behaviours about biosecurity. Several different response formats were provided, to be consistent with the categories used in the Colmar Brunton survey, and according to what was most appropriate for each question, as displayed in Table 1. For reporting of the results, all questions were scored on a scale out of 7, for consistency and ease of interpretation (this required recoding of those items rated on the 5 and 10-point scales).

Table 1. Topics of questions asked in the local community biosecurity survey, and the format of the response. 
Question topic

Self-rated understanding of biosecurity*

Perceptions about what the biosecurity system involves (includes 11 items, such as 'Specifying requirements that must be met before products can be imported')*

Perceived threat posed by biosecurity, to New Zealand, the PoT and themselves/their family

Perception of whether they could make a difference for biosecurity (termed 'perceived self-efficacy')

Perceived importance of biosecurity for New Zealand*

Self-rated confidence that they know what to do if they find a pest, where to look for information, and how to spot potential biosecurity threats*

Actual biosecurity related behaviour in the past year (searching for information, accessing information and attending events, pest or weed control efforts)*

How easy it is to find and understand biosecurity related information*

What they would do if they found an incursion*

Role and responsibility of different people in the biosecurity system (including government, NGOs, Community groups, New Zealand businesses, you and your family, and iwi)*

Barriers to greater participation in biosecurity efforts*

Demographics including age, gender, level of education, ethnicity and household income
Response format

Scale of 0 - I don't understand [biosecurity] at all to 10 - I know exactly what [biosecurity] means.

Participants rate whether items are 'Definitely not', 'Maybe' or 'Definitely' included in the biosecurity system.

7-point Likert scale from Strongly disagree to Neutral to Strongly agree.

7-point Likert scale from Strongly disagree to Strongly agree.

Scale of 0 - Not at all important to $10-$ Extremely important.

5-point Likert scale from Strongly disagree to Strongly agree.

Yes or No, or for pest and weed control efforts, frequency (Never, Not in the past year, Once or twice, Several times, Many times)

5-point Likert scale from Strongly Disagree to Strongly agree

Multiple choice (e.g. Contact the authorities, research it yourself, Do nothing)

5-point Likert scale from No role at all to A large role

Multiple choice (e.g. I don't know what I can do to make a difference, I do not have time/too busy, Lack of knowledge)

Multiple choice

\section{Survey administration}

The survey was hosted on the platform SurveyMonkey ${ }^{\circledR}$ and advertised to the local community via social media platforms Facebook and Instagram, for a duration of two weeks. Geolocated targeting was used to ensure only Mount Maunganui residents (the $\sim 15,000$ in the immediate vicinity of the PoT) were given the opportunity to participate in the survey. Participation was incentivised by the chance to win one of ten $\$ 100$ supermarket vouchers awarded randomly among the participant pool.

\section{Data analysis}

Survey data were analysed using SurveyMonkey® software, which provided descriptive statistics of frequency counts, mean scores, weighted averages, percentages, and standard deviations, where appropriate.

\section{Results}

\section{Demographics}


A total of 324 local community members responded to the biosecurity survey. The number of participants who responded to individual survey questions varied, from 325 to 315 (excepting the option to give further comments, to which only 84 participants responded). The median age was 49 , approximately 12 years older than the national median (Statistics New Zealand 2017). Females comprised $55.2 \%$ of the sample while nationally they comprise $50.7 \%$ of the population (Statistics New Zealand, 2017). The sample also had a larger proportion of persons who had achieved higher education, relative to national statistics (Ministry of Education 2019). The largest group of the survey sample identified their ethnicity as Pākehā/NZ European (87.3\%), which is higher than the national average (70.2\%), while a more representative sample of Māori participants was gained (14\% versus 16.5\% nationally) (Statistics New Zealand, 2018). The most common annual income bracket reported by participants was $\$ 50,000-\$ 100,000$ (31.6\% of participants), while the national average annual household income is $\$ 100,103$ (Statistics New Zealand 2017).

\section{Understanding of biosecurity}

The local community rated their understanding of the term biosecurity as moderate, with a mean of 5.1 out of 7 . The results are displayed in Figure 1, listed from least to most likely to be perceived as included the biosecurity system. Participants were more certain that gathering and promoting information about biosecurity was part of the biosecurity system, than direct biosecurity surveillance. Participants expressed a higher degree of uncertainty as to whether the more abstract applications of biosecurity were included in the biosecurity system, such as protecting our wellbeing, and applying Treaty of Waitangi principles (the binding treaty for indigenous Māori of New Zealand) or tikanga (Māori knowledge and values). A substantial $25 \%$ of participants were unsure whether "Everyone being vigilant and reporting suspicious pests, weeds or diseases" was included in biosecurity.

\section{Significance and importance of biosecurity}

Despite varied understandings of biosecurity, the local community did report it as a significant threat to New Zealand as a whole (mean of 6.8 out of 7), to the PoT (6.7 out of 7), and to themselves or their families (6.4 out of 7). They perceived this threat as less the closer it was to themselves, but overall, still agreed or strongly agreed biosecurity was a threat at all three levels. When asked how important they thought biosecurity was, the community rated it very important, with an average of 6.8 out of 7 .

\section{Perceptions of biosecurity role, knowledge, and behaviour}

When asked if they could help make a difference for biosecurity, local community members agreed that, on average, they could make a difference (5.9 out of 7). They were also relatively confident that they knew what to do if they found an unwanted pest, weed or disease in New Zealand (5.9 out of 7). This is consistent with the national sample, where $59 \%$ agreed or strongly agreed they know what they should do (Colmar Brunton 2018).

On the other hand, close to one-fifth of Mount Maunganui community members $(17.7 \%)$ disagreed or were neutral as to whether they could make a difference, and the same percentage disagreed or were neutral that they knew what to do if they found an unwanted pest or disease. The two most common reasons listed as barriers to taking biosecurity action were not knowing what to do to help make a difference (45.9\%), and a lack of knowledge about biosecurity (46.5\%). Only $22 \%[3]$ of participants reported that they do not have time or were too busy to help. A very small minority reported that biosecurity is not their problem (1.3\%), a potential incursion would not affect them (1\%), or that what they can do would not make a difference overall (3.8\%).

Mount Maunganui community members were relatively confident that they could identify the main biosecurity threats (38\% agreed), relative to the national population (29\%). Consistent with the national sample, $54 \%$ of participants said that if they noticed an unwanted pest, weed or disease tomorrow, their first reaction would be to contact the 
authorities. Mount residents were less inclined to say they would research it themselves (36\% versus $49 \%$ nationally), and less likely to contact an individual or organisation they trust about biosecurity (23\% versus $29 \%$ nationally). Only $10 \%$ of local residents disagreed that they knew what to do if they found a potential incursion, suggesting most of the local community are confident regarding appropriate biosecurity actions.

Regarding proactive biosecurity behaviours, one third of participants (32.1\%) reported that they had actively sought or asked for information about pests, weeds and diseases in the past year. This was higher than the national average, where only $24 \%$ had actively sought information. When asked if they had seen, read or heard something about pests, weeds and diseases (passive information exposure) 83.3\%. of the local community surveyed responded yes. Thus, a majority of local community members had been exposed to material about biosecurity in the past year. This rate is markedly higher than the national average, where only $50 \%$ recalled hearing, seeing or reading something about biosecurity. Mount Maunganui residents also tended to agree this information about biosecurity was easy to find (average of 4.9 out of 7 ) and easy to understand (5.2 out of 7).

Local community members were also asked about biosecurity-related behaviours that they are currently performing or had performed over the past 12 months. Approximately half (48\%) reported taking action to control pests or weeds at least once or twice in the past year, on their own property. A further $25.6 \%$ had not taken action in the past year, but had prior to this, while $26.5 \%$ had never taken actions to control pests or weeds on their own property. Community members reported less action outside of their own properties, with $28.9 \%$ having taken action in the last year and $28.8 \%$ having taken action to control pests or weeds at some prior stage. These rates are comparable to national averages.

Finally, local community members were presented with a list of stakeholders and asked to rate how large a role they thought the stakeholder should play in biosecurity, from no role (1) to a large role (7). Government was clearly identified as the group that should have the most significant role (6.6 out of 7 ), with $81.6 \%$ of participants rating they should have a large role. Non-governmental organisations were also expected to play a significant part, with $44 \%$ of participants rating they should have a large role (average 5.8 out of 7), followed by community groups (5.5 out of 7) and businesses (5.2 out of 7). Interestingly, participants were less certain about whether they themselves should have a role (4.8 out of 7 ), and whether local iwi, hapū and marae should be involved (5 out of 7).

\section{Discussion}

While the local community were moderately confident about their understanding of biosecurity, the lack of agreement and uncertainty regarding what is included in the biosecurity system suggest there is significant room for improvement in this understanding. This is particularly the case given the government's emphasis on the role of citizen science, and the uncertainty from participants as to whether citizen's assisting with surveillance constitutes biosecurity. It is also curious that although on average participants rate that they can make a difference for biosecurity, they appear unsure whether they should be playing this role, rating many groups as having a larger responsibility than themselves (including government, NGOs, community groups and businesses).

There was also confusion regarding cultural aspects of biosecurity, such as the extent to which Māori knowledge and equal representation for Māori were related to biosecurity. It appears that perceived accountability for biosecurity in New Zealand is both dispersed, and complex, with wide-ranging opinions about who responsibility sits with, particularly with regard to involvement of indigenous groups. This is reminiscent of the national Colmar Brunton (2018) survey which indicated people were most likely to mention the environmental and economic impacts of a biosecurity breach, as opposed to cultural or social aspects, which may be less considered. Participants also rated preborder and border activities as more clearly biosecurity than post-border elements such as multi-stakeholder 
involvement and protecting the wellbeing of New Zealanders. These findings suggest a need to broaden the community's conception of biosecurity, as an underpinning part of a broader system which is fundamentally connected to all aspects of our wellbeing. Awareness-raising efforts may also be targeted at ensuring community members are aware that biosecurity involves everyone.

On a positive note, most participants had been exposed to information about biosecurity and one-third had actively sought out information. Moreover, half had taken action to support biosecurity efforts in the year prior to the survey. It may be that local biosecurity initiatives[4] are having an impact, or that Mount residents may be particularly attentive to national-level campaigns, possibly due to an awareness of how fragile their local environment is, through past events such as the Rena oil spill which affected the surrounding region (Smith, Hamerton, Hunt \& Sargisson 2015). Either way, this supports the notion that community members are enthusiastic about helping the biosecurity cause, and would like to work to address the key barriers inhibiting their participation; lack of knowledge, and not knowing what to do.

The present research suggests awareness campaigns are likely to be well received, given community members are concerned about biosecurity, think it is important, and believe they can help to make a difference. The high degree of perceived self-efficacy (belief that they can make a difference) and confidence in biosecurity action suggests that a majority of community members (around $80 \%$ ) would be amenable to contributing to the biosecurity cause. Further research is needed to ascertain whether participants self-reported knowledge of the main biosecurity threats can be substantiated, particularly given these are higher than the national population survey. Campaigns should focus on what the key threats are, how to report them, and how to otherwise help with biosecurity (surveillance, trapping, weeding, etc).

Finally, there is a sub-group of participants who are uncertain and lacking confidence surrounding biosecurity; they are unsure whether they can make a material difference, and do not know what to do to help. Further research is needed to ascertain whether these are the "blissfully ignorant" proportion of the population identified in the national biosecurity survey, or whether they are interested in learning more (Colmar Brunton 2018 p. 39). It may be most beneficial to target the majority of the community who are interested and engaged in protecting New Zealand from biosecurity threats.

[1] Defined as being between Mount Maunganui itself and Sunrise Avenue/Hibiscus Avenue, approximately ten kilometres down the coast.

[2] See Biosecurity 2025 Implementation Plan, p. 10. Retrieved from https://www.thisisus.nz/get-involved/resources/

[3] Participants could tick multiple options therefore percentages do not add to 100.

[4] For example, see http://www.tmbiosecurity.co.nz/

\section{Study 2: School Children}

The following sections focus on Study 2 involving school children, including data collection methods, results, discussion and summary. A final summary is then provided highlighting the key findings across the studies.

\section{Method}

\section{The biosecurity education kit}

An educational biosecurity kit called 'Invasion Busters' was developed by the House of Science, a charitable trust in New Zealand which provides 'hands-on' science resource kits. The Invasion Busters kit was designed by the Resource Developer (previously a medical microbiologist), and informed by a population ecologist. The kit was targeted at children aged five to 12 years old (years 1 to 8 ) and included seven activities in total, varying in difficultly to cater to 
the broad age range. Six activities were related to different components of the biosecurity system, such as sorting and identifying seeds at the border, identifying pest threats (the brown marmorated stink bug, set in clear resin), and modelling insect population growth. The final activity in the kit is a board game where children collaborate to keep incoming pest threats under control, given the different 'roles' they are assigned, such as biosecurity officers, stevedores (who unload goods on port), insect trappers, and incursion investigators. Pests included in the game are real current pest threats and are accompanied by information such as the potential threat they pose, country of origin, and damage they can do to host plants. An example of the 'role cards' and 'pest cards' from the game are displayed in Figure 2.

The Invasion Busters biosecurity education kit was piloted in schools around the Tauranga area in March and April of 2018. The data for this evaluation were collected from the classrooms who piloted the kit, because these teachers attended a 'launch' of the kit, where they were informed of the evaluation. The teachers therefore had an understanding and appreciation of the purpose of the evaluation and would be more likely to administer the questionnaires using the requested method.

\section{The biosecurity kit survey questionnaire}

Questionnaires to evaluate the education kit were administered three times; once immediately before the kit was introduced (e.g. on a Monday morning), once immediately after use of the kit (e.g. on a Friday afternoon, after using the kit several days that week) and once six months later, to test retention of knowledge. These measures will be referred to as the pre, post, and follow-up measures hereafter. The questionnaires were sent out with the kit for the pre and post measures, and teachers were re-contacted and sent the questionnaires again for the follow-up measure. Instructions for administration were included with the survey, including a request for teachers to assist with survey comprehension and completion, without explaining the answers to the questions (including avoiding explaining what biosecurity meant, prior to using the kit). The follow-up measure packet included reminder instructions for administration, a recap purpose statement and return envelopes, in addition to a list of names of the children in the class who needed to complete the questionnaire (based on children who had informed consent from their parents and had completed both the pre and post measures).

The questionnaires included two types of questions, the first being a Likert-scale question using a 5-point smiley-face Likert scale combined with word based 'degrees of agreement' as anchors (see Figure 3). This scale was used because evidence shows that children have greater engagement with smiley face Likert scales than other evaluation instruments (e.g. scales solely using words as anchors), and 5-point smiley face Likerts are recommended for children (Hall \& Hume 2016).

There were nine questions rated on the smiley face Likert scale. These statements were designed to be concrete rather than abstract (avoiding 'feeling' statements), as research suggests that both younger and older children (age range 612) understand graded scales when making judgements about more concrete concepts (Mellor \& Moore 2014). The teacher also assisted children's understanding by reading the questions aloud. These included "I know what biosecurity is" and "My family talk about stopping bad insects from hurting animals, plants, or people in New Zealand".

There were a further eight short answer questions, designed to move beyond self-perceptions and test existing knowledge and retention of knowledge. These related to specific activities within the kit, for example "Can you name three bad insects we don't want to come into New Zealand?", and "Can you think of something which might make bad insects grow faster or have lots of babies?". Children should have learnt the answers to these questions while using the kit, for example three current insect pest threats through the 'Invasion Busters' board game, and factors which 
affect insect population growth in the population modelling activity. Teachers were asked to identify which activities they completed (and did not complete) on a form delivered with the questionnaires, so this could be considered in the data analysis.

\section{Data cleaning and analysis}

Data from a total of 48 children were removed from the study, due to issues with data continuity and quality. This included 37 children who had completed either a pre or a post-kit survey but not both, and 11 students (one classroom) where the pre-kit survey was administered after use of the kit, rather than before. This was evident in children's answers, which included direct quotes from the kit, such as 'Catch it, snap it, report it', a catch phrase from a local biosecurity initiative (Kiwifruit Vine Health). Removal of these students left a total sample size of 120 children.

For the Likert-scale questions, the scores were analysed using repeated measures fitted as a linear mixed model in Genstat 19. To account for correlation between measurements taken for the same child (pre, post and follow-up measure), an unstructured correlation model was used. Random effects (constrained to be positive) were included to account for school, teacher, age at pre-test (as a factor) and gender variation. The fixed term assessed was 'survey session', a factor with three levels (pre, post and follow-up measure). In addition, Fisher's unprotected least significant differences at the $5 \%$ level were used to compare the predicted means. Residual plots were assessed to check that the assumptions of normality and constant variance broadly held and data for each question were analysed independently.

For the short answer questions, scoring was more difficult. Due to the diversity of the answers provided (some being very creative), the research team assembled to decide what constituted a 'correct' answer for each question. This was a difficult task, as often children identified 'bad' insects (such as wasps or tarantulas) as pests, however a majority are not considered 'biosecurity pests' because they may already be in New Zealand, or are not on an 'unwanted' pest list for New Zealand. Children also provided varying levels of detail in their responses, which demonstrated varying degrees of knowledge. For example, children were asked to identify the difference between a brown marmorated stink

bug (key current pest threat for New Zealand), and a regular stink bug. This was the basis of one of the activities in the kit. Many children wrote 'colour' or 'size', which, while correct, does not provide sufficient evidence that they would be capable of successfully differentiating a brown marmorated stink bug from a regular stink bug in real life. Other children wrote "the brown marmorated stink bug has three white spots", which is a much more specific, and correct, answer. This variance and subjectivity of responses was managed by creating an 'inventory' of all answers provided, for each question. Each inventory was then marked by two independent raters, as to whether answers were correct (one point given), partially correct (half point given, indicating understanding of the underlying premise), or incorrect (zero points given). Discrepancies in ratings were discussed and resolved, to ensure ratings were consistent. All responses were then given a numeric score, which allowed use of the same method of statistical analyses as for the Likert scale questions above.

\section{Results}

\section{Demographics}

One hundred and twenty children participated in the research, spread across three schools in the Tauranga area[1], with a total of six teachers across the children. The schools were deciles[2] 4 (32\% of children), 6 (23\% of children) and 9 (45\% of children). Children ranged from six to ten years old, with the largest number aged 7-8 years old, as displayed in Figure 4. There were equal numbers of boys and girls (60 each). 
Results for the smiley face Likert scale questions are reported in graph format (see Figure 5). For five of the eight questions children showed a statistically significant improvement over time, for two questions there was no difference, and for one question, children showed a decline in correct answers at the six-month follow up.

After using the kit, children demonstrated an increase in their self-rated understanding of biosecurity $\left(t_{87}=12.7 ; p<.001\right)$, and this was retained six months later $\left(t_{87}=11.1 ; p<.001\right)$. Children were also more likely to rate that they understood 'that some insects can hurt other animals, plants or people', however this was only significant between the pre-test and the follow-up $\left(t_{87}=11.1 ; p<.001\right)$. This finding triangulates with the first question as a proxy measure for biosecurity understanding, reinforcing that understanding did improve. Children appeared less confident in their understanding when the term 'biosecurity' was used, as opposed to the general statement that insects may cause harm, which is a simpler explanation of the premise of biosecurity.

Children demonstrated an increased and sustained recognition of the importance of border surveillance for biosecurity risks, acknowledging 'it is important to stop new insects coming into New Zealand' (pre vs post $t_{80}=5.9$; $p<.001$ ) (post vs follow up $\left.t_{80}=6.1 ; p<.001\right)$. On the other hand, children's ratings for biosecurity behaviours did not significantly improve, with no change in likelihood of reporting potential biosecurity incursions or talking with family about biosecurity. Surprisingly, the third biosecurity behaviour, 'looking for insects around home or school' actually saw a significant decrease six months after completing the kit, relative to before using the kit, where a majority of children reported they did not look for insects at school or at home $\left(t_{87}=-3.3 ; p=.001\right)$.

The final measurements on the Likert scale relate to knowledge of insect pests ('which insects might hurt animals, plants or people'), and knowledge of appropriate reporting protocols ('I know what to do if I see a bad insect'). Immediately after completing the kit, there was weak evidence that self-rated knowledge of pest insects had increased $\left(t_{90}=1.7 ; p=.097\right)$, although this was not maintained at the follow-up. However, when asked to name current pest threats directly (rather than self-rating their confidence about naming pests), children demonstrated a significant improvement, both immediately after using the kit $\left(t_{87}=3.5 ; p<.001\right)$, and at the follow-up $\left(t_{87}=3.7 ; p<.001\right)$. This result is substantiated in that children were more than twice as likely to name the stink bug as a pest (featured in the kit), after using the kit. Children did demonstrate increased confidence in their knowledge of reporting protocols $\left(t_{92}=3.1\right.$; $\mathrm{p}=.002$ ), however this was not maintained at follow-up. Finally, children were better at identifying incursion pathways, both after using the kit $\left(t_{93}=6.7 ; p<.001\right)$ and at the follow-up $\left(t_{93}=5.7 ; p<.001\right)$. These results are displayed in Figures 5 and 6.

Further questions where children demonstrated improved knowledge included differentiating the brown marmorated stink bug from regular stink bugs (pre vs post $t_{91}=5.6 ; p<.001$ ) (post vs follow-up $t_{91}=5.1 ; p<.001$ ), naming locations one might find insects (pre vs post $t_{167}=3.1 ; p=.002$ ) (post vs follow-up $t_{167}=2.1 ; p=.04$ ), and identifying potential biosecurity strategies for New Zealand (pre vs post $t_{93}=3.8, p<.001$ ) (post vs follow-up $t_{93}=4.0 ; p<.001$ ) as shown in Figure 7. Some of these questions were clearly more complex, with considerably lower baseline averages (differentiating stink bug and identifying biosecurity strategies), however demonstrated marked improvements over time. Children's answers also demonstrated highly creative thinking, where some individuals (perhaps unknowingly) identified or alluded to sophisticated biosecurity control mechanisms currently used by New Zealand. This included "getting their DNA", "spray smoke in their eyes so they can't see" (fumigation), and "releasing a new species of insect and make it eat it" (biological control). Other humorous answers are displayed in Table 2. Overall, the children demonstrated a good awareness of current border biosecurity measures, such as checking bags, disposing of food before entering the country, and pest trapping. 
Despite using the Likert scale to indicate they did not feel an increased confidence in knowing what to do if they saw a pest threat, children were significantly better at identifying correct biosecurity behaviours after using the kit. This included reporting (telling someone, such as an adult), trapping, or killing the pest (the least encouraged response, but marked as correct).

There were two final questions where children showed no improvement over time. These were 'Can you name a trap we might use to catch a bad insect?', and 'Can you think of something which might make bad insects grow faster or have lots of babies?'. These questions were related to specific activities within the kit, where children got to build and use insect traps, and do population modelling, where changes in different variables in the environment affected population growth. They were therefore reliant on the extent to which they had completed these activities, which will have varied between classrooms, and may explain the absence of change. Many children did provide accurate answers to this question which indicated an understanding of the premise, particularly around providing a food source for the insects, inaction ("not killing") and mating with other insects.

Table 2 Examples of children's responses to various survey questions

\section{Q. Can you name a trap we could use to catch a bad insect?}

A.

- When it is sleeping tie a string around it

- Sleep smoke

- A rat trap with fly spray in it

- A micronet

Q. Can you name a way that bad insects could get into NZ?

A.

- Ride on fish

- They could walk in a group

- Camouflage

Q. What should you do if you see a bad insect?

A.

- Call for help and tell the pound

- Tell your mum

- Step on it and say goodnight

Q. Can you think of something which might make bad insects grow faster or have lots of babies?

A.

- Finding a wife or husband

- Hope

- Eating, killing and stealing

- Eat, eat, eat and eat

Q. Can you think of something we could do to stop bad insects from coming into NZ?

A.

- Build a wall like Donald Trump did

- Releasing a new species of insect and make it eat it

- Make a force field around NZ

- Putting smoke in their eyes so they can't see

- Make robots that search for them in NZ

- Make the government stop them 


\section{Discussion}

The biosecurity kit was successful at improving children's understanding of biosecurity, perceived importance of biosecurity, and their critical knowledge about biosecurity, including current pest threats, incursion pathways, and biosecurity control strategies. The kit was somewhat less successful at improving biosecurity behaviours, with no change in reporting behaviours, or discussion with family about biosecurity. Further, there was a decrease in the likelihood that children would search for insects at home or school, however one possible explanation for this finding may be seasonal differences - the six-month post measure was undertaken during early spring and therefore children may have spent less time outdoors during this period due to rain or colder temperatures. Overall, these results suggest the kit is an excellent learning resource, but is less effective as a behaviour change tool, as least without additional interventions, such as encouragement from parents to keep looking for and discussing insects or pests at home. With this additional support, it may be that the kit would have greater spill-over benefits, in generating interest and learnings for parents, siblings and others living in the home.

The findings also provided some key learnings about measurement of biosecurity learnings among children. The term biosecurity may be a barrier for some children, as children were more likely to rate that they understood the premise of biosecurity, rather than the term itself. This may emphasise a need to reduce jargon when communicating about biosecurity with children, and in particular when measuring children's understanding of the concept, to gain an accurate measure. Similarly, there was some contradiction apparent in children's self-rated knowledge about biosecurity, versus their actual performance when providing short answers. That is, while children rated that they did not have significantly greater knowledge after completing the kit, their answers indicated that they did in fact increase and retain biosecurity knowledge. This suggests that a short answer format may be more accurate than self-ratings, and that children underestimated the amount of learning they achieved through the kit.

[1] Schools will remain unnamed, for discretion and confidentiality purposes.

[2] School deciles are a measure of the socio-economic positions of a school's student community, where decile 1 schools are the $10 \%$ with the highest proportion of students from low socio-economic communities.

\section{Summary Of Study 1 And 2}

This research provides evidence of two potential target groups for citizen science surrounding biosecurity; adult members of the local community (public) and school children. Both groups demonstrated a moderate level of understanding of biosecurity, and a very high understanding of the importance of biosecurity for protecting New Zealand. They report moderate awareness regarding current pest threats and appropriate reporting protocols, however low rates of actual performance of biosecurity-related behaviours, including surveillance, management, and having discussions about biosecurity. This suggests that interventions now need to shift focus from the early stage awareness raising, into provision of straight-forward advice regarding what they can practically do to help. It will also be beneficial to continue education regarding current pest threats and appropriate biosecurity behaviours. Overall these results are highly positive, as they suggest a willingness and interest to help, with the key barrier for these groups being not knowing what more they can do, or how they should do it.

\section{Limitations}

There are several potential limitations to this research, which relate to the sampling and surveying methods used. First, it was difficult to gain a sufficiently large sample which was also representative, for both the local community members and school children. Using social media to recruit local community members is likely to have resulted in a slightly different sample than alternative methods such as collecting data in person 'on-the-ground'. The statistics 
comparing our sample with national demographics suggested a slight overrepresentation of women, and a skew toward older participants. Nevertheless, comparison with the Colmar Brunton national biosecurity survey saw similar results, suggesting the sample provided a reasonable measure for the local community situated at Mount Maunganui.

Collecting data with children is always a difficult task which requires careful consideration. Our sample is relatively small, due to the need for informed consent, and participation on three different occasions from each participant. The researchers were also mindful of any responses which appeared invalid (i.e. initial survey administration occurred after use of the kit). Meeting these requirements resulted in removal of many participants, to ensure the data used was both ethical and sound.

The second concern related to accurately measuring children's perceptions, knowledge, awareness and behaviours of biosecurity. This required the design of survey questions and survey scales which were both easy to understand and easy to respond to. In the survey question design, use of jargon was minimised, and complex concepts were translated into simple terms (e.g. population modelling of insect reproduction was phrased 'have lots of babies'). Answers indicated that most children who responded to the open-ended questions understood the concept being assessed. It was clear that some children struggled to communicate their knowledge and may have scored better on the questions if they had assistance to write or read their responses (for example children who spelled words phonetically which made answers difficult to interpret e.g. "soga bug" for 'soldier bug').

Responses on the smiley face Likert were more difficult to assess. The smiley face Likert scale utilised here is widely used in research involving children, however is known to bring a number of issues, such as garnering different responses from different age children (varying language abilities) and acquiescence bias (for example see Hall et al. 2016; Mellor \& Moore 2014; Read \& MacFarlane 2006). For this reason, this scale was combined with the open-ended free recall questions, to triangulate against and complement the Likert scale responses, to provide a more complete picture.

Finally, the extent to which the children absorbed the information from the biosecurity kit and were able to recall this information will have depended partly on the teacher who administered it, and which activities were completed. These variables are difficult to control and may have impacted the results.

\section{Declarations}

\section{Ethics and informed consent}

Ethical approval for this research was gained through AgResearch's human ethics committee. Local community members who did not provide their informed consent at the beginning of the survey were excluded from participating.

All children who were invited to participate were sent home with an informed consent form, for their parent(s) or legal guardian to approve their participation in this study. This form included a description of the research, and explained that children's identities would remain confidential, with average age and gender statistics being the only details reported. One consent form was sought for each child's participation throughout the research. Any data attained from children who did not have signed informed consent from their parent or legal guardian was not included in this study.

\section{Acknowledgements}

The authors would like to thank AgResearch for providing funding for this research, through the Strategic Science Investment Fund, and as part of the Better Border Biosecurity (B3 Programme). 


\section{Funding}

This research was funded through AgResearch's Strategic Science Investment Fund, as part of the Better Border Biosecurity (B3) Programme.

\section{Conflicts of interest/Competing interests}

The authors are not aware of any conflicts of interest or competing interests.

\section{Availability of data and material}

The data is not available due to confidentiality issues, but the authors are happy to discuss the material.

\section{Code availability}

Not applicable.

\section{Authors' contributions}

Research ideation/underpinning research: John Kean, Bruce Small, Penny Payne

Data collection: Penny Payne, John Kean, Susanna Finlay-Smit, Bruce Small

Data analysis: Penny Payne, Vanessa Cave, Susanna Finlay-Smits, Bruce Small

Writing: Penny Payne, Susanna Finlay-Smits

Reviewing: Penny Payne, Susanna Finlay-Smits, John Kean, Bruce Small

\section{Ethical approval}

Ethical approval for this research was provided through the AgResearch Human Ethics Committee.

\section{Consent to participate}

All participants or legal guardians of the participants in this study gave their consent to participate.

\section{Consent for publication}

All authors gave their consent for this material to be published.

\section{References}

1. Campbell M, Bryant D, \& Hewitt C (2017) Biosecurity messages are lost in translation to citizens: Implications for devolving management to citizens. PloS ONE 12(4): 9. https://doi. org/10.1371/journal.pone.0175439

2. Colmar Brunton (2018) Biosecurity 2025 - Strategic Direction: A biosecurity team of 4.7 million public survey. Report produced by Colmar Brunton for Biosecurity New Zealand, Ministry for Primary Industries, on behalf of Biosecurity 2025

3. Department of Agriculture and Water Resources (2018) Biosecurity Innovation Exchange: 2018 forum summary. Report produced by Department of Agriculture and Water Resources (Australian Government) 
4. du Plessis E, Granados GM, Barnes I et al. (2019) The pandemic strain of Austropuccinia psidii causes myrtle rust in New Zealand and Singapore. Australasian Plant Pathol 48: 253-256. https://doi.org/10.1007/s13313-0190624-x

5. Evans C, Abrams E, Reitsma Roux K, Salmonsen L \& Marra P (2005) The neighbourhood nestwatch programme: Participant outcomes of a citizen science ecological research project. Conservation Biology 19(3): 589-594

6. Froud K, Oliver T, Bingham P, Flynn A \& Roswell N (2008) Passive surveillance of new exotic pests and diseases in New Zealand. In Froud K, Popay A \& Zydenbos S (eds.). Surveillance for biosecurity: Pre-border to pest management. New Zealand Plant Protection Society, Paihia, 97-110.

7. Gallo T \& Waitt D (2011) Creating a successful citizen science model to detect and report invasive species. BioScience 61(6): 459-465

8. Hall L, Hume C \& Tazzyman S (2016) Five degrees of happiness: Effective smiley face Likert scales for evaluating with children. Conference paper presented at the $15^{\text {th }}$ International Conference, June 21-24, Manchester, United Kingdom. DOI 10.1145/2930674.2930719

9. Mellor D \& Moore K (2014) The use of likert scales with children. Journal of Pediatric Psychology 39(3): 369379. doi.org/10.1093/jpepsy/jst079

10. Ministry for Primary Industries (2016) Biosecurity 2025 direction statement for New Zealand's biosecurity system. Ministry for Primary Industries, Wellington. Retrieved from http://www.biosecurity2025.nz/assets/Resources/b88e5cb1 fa/Biosecurity-2025-Direction-Statement-2016web.pdf

11. Ministry for Primary Industries (2018a) Mycoplasma bovis update: Biosecurity New Zealand. Retrieved from https://www.biosecurity.govt.nz/protection-and-response/mycoplasma-bovis/situation-report/

12. Ministry for Primary Industries (2018b) Media release: Myrtle rust operation intensifies in bid to contain the disease. Retrieved from https://www.mpi.govt.nz/news-and-resources/media-releases/myrtle-rust-operationintensifies-in-bid-to-contain-the-disease/

13. Ministry for Primary Industries (2018c) Protect your farm from disease. Retrieved from https://www.biosecurity.govt.nz/protection-and-response/mycoplasma-bovis/advice-on-mycoplasmabovis/advice-about-mycoplasma-bovis-for-farmers/

14. Ministry of Education (2019) Educational attainment in the adult population: Highest education attainment of the New Zealand population aged 15 years and over. Retrieved from https://www.educationcounts.govt.nz/statistics/indicators/data/education-and-learning-outcomes/3680

15. Newman C, Buesching CD \& Macdonald DW (2003) Validating mammal monitoring methods and assessing performance of volunteers in wildlife conservation - "Sed quiz custodiet ipsos custodies? Biological Conversation 113: $189-197$

16. Port of Tauranga (2017) Company profile Tauranga, NZ. Retrieved from https://www.port-tauranga.co.nz/newsand-media/archive/

17. Ram R, France B \& Birdsall S (2015) Why biosecurity matters: Students' knowledge of biosecurity and implications for future engagement with biosecurity initiatives. Research in Science and Technological Innovation 34(1): 69-84

18. Read J \& MacFarlane S (2006) Using the fun toolkit and other survey methods to gather opinions in child computer interaction. Proceedings of the 2006 Conference on Interaction and Design and Children June 7-9, Tampere, Finland

19. Smith H (2017) Risk posed by different vector types for the spread of Kauri Dieback: A risk analysis on interactions that are suspected to threaten Kauri. Keep Kauri Standing: Stop Kauri Dieback Disease Spreading. 
Retrieved from https://www.kauridieback.co.nz/media/1522/17-kauri-dieback-risk-analysis-report-final-3_3_17.pdf

20. Smith K, Hamerton H, Hunt S \& Sargisson R (2015) Local volunteers respond to the Rena oil spill in Maketū, New Zealand. Kōtuitui: New Zealand Journal of Social Sciences 11(1) doi.org/10.1080/1177083X.2015.1009474

21. Statistics New Zealand (2017) Summary figures for the New Zealand resident population, year ended December 2017. Retrieved from https://www.stats.govt.nz/topics/population and https://www.stats.govt.nz/informationreleases/household-income-and-housing-cost-statistics-year-ended-june-2017

22. Statistics New Zealand (2018) New Zealand's population reflects growing diversity, 2018 Census data. Retrieved from https://www.stats.govt.nz/news/new-zealands-population-reflects-growingdiversity\#: :text=According\%20to\%20the\%202018\%20Census,ethnic\%20population\%20continues\%20to\%20grow.

23. Thomas ML, Gunawardene N, Horton K, Williams A, O'Connor S, McKirdy S \& van der Merwe J (2017) Many eyes on the ground: Citizen science is an effective early detection tool for biosecurity. Biological Invasions 19: 27512765

24. Tulloch A, Possingham H, Joseph LN, Szabo J \& Martin T (2013) Realising the full potential of citizen science monitoring programs. Biological Conservation 165: 128-138

25. Urquhart J, Potter C, Barnett J, Fellenor J, Mumford J, Quine CP \& Bayliss H (2017) Awareness, concern and willingness to adopt biosecure behaviours: Public perceptions of invasive tree pests and pathogens in the UK. Biological Invasions 19: 2567-2582

\section{Figures}


Tikanga training (training in Māori values) for biosecurity professionals

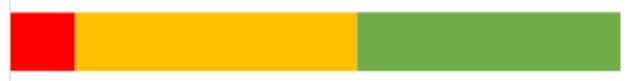

The Treaty of Waitangi and its principles

Tribal knowledge and protocols about the environment and looking after it

Protecting the wellbeing of whanau and family

A wide range of participants such as government agencies, businesses, Māori, community groups, and the public

Everyone being vigilant and reporting suspicious pest, weeds, or diseases

Inspection of cargo before and after it arrives in New Zealand, and before it is sent to its final destination

Ongoing surveillance and testing within New Zealand
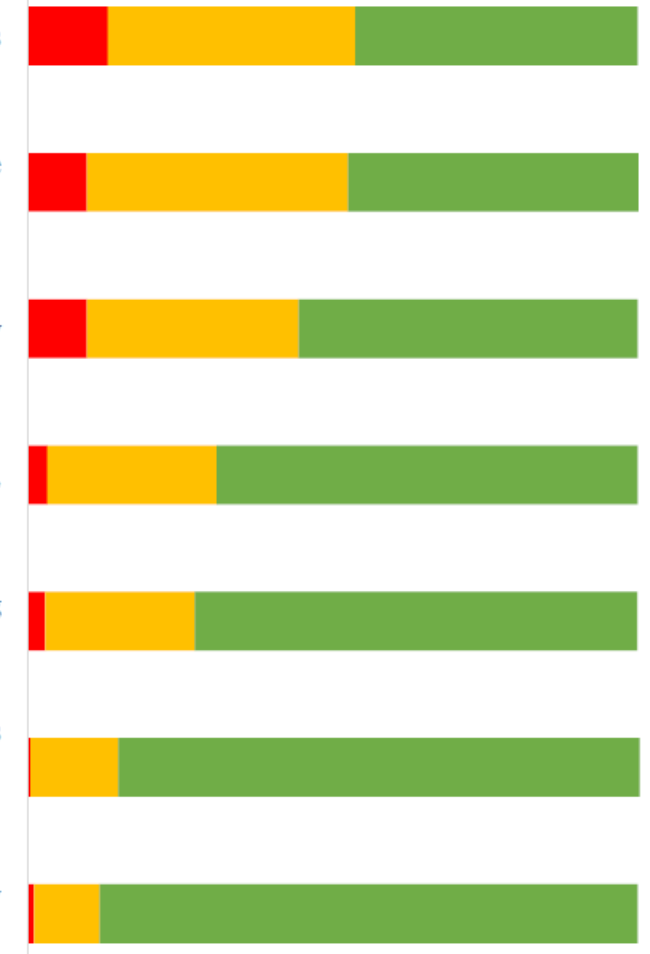

Public education campaigns at ports and airports to encourage people to declare or dispose of items that may contain pests, weeds or diseases

Specifying requirements that must be met before products can be imported

Gathering information on pests, weeds and diseases that pose a risk to New Zealand

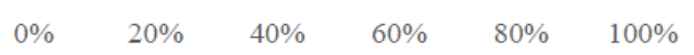

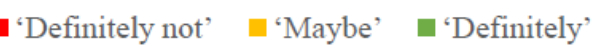

\section{Figure 1}

Local community perceptions about what is included in the biosecurity system 

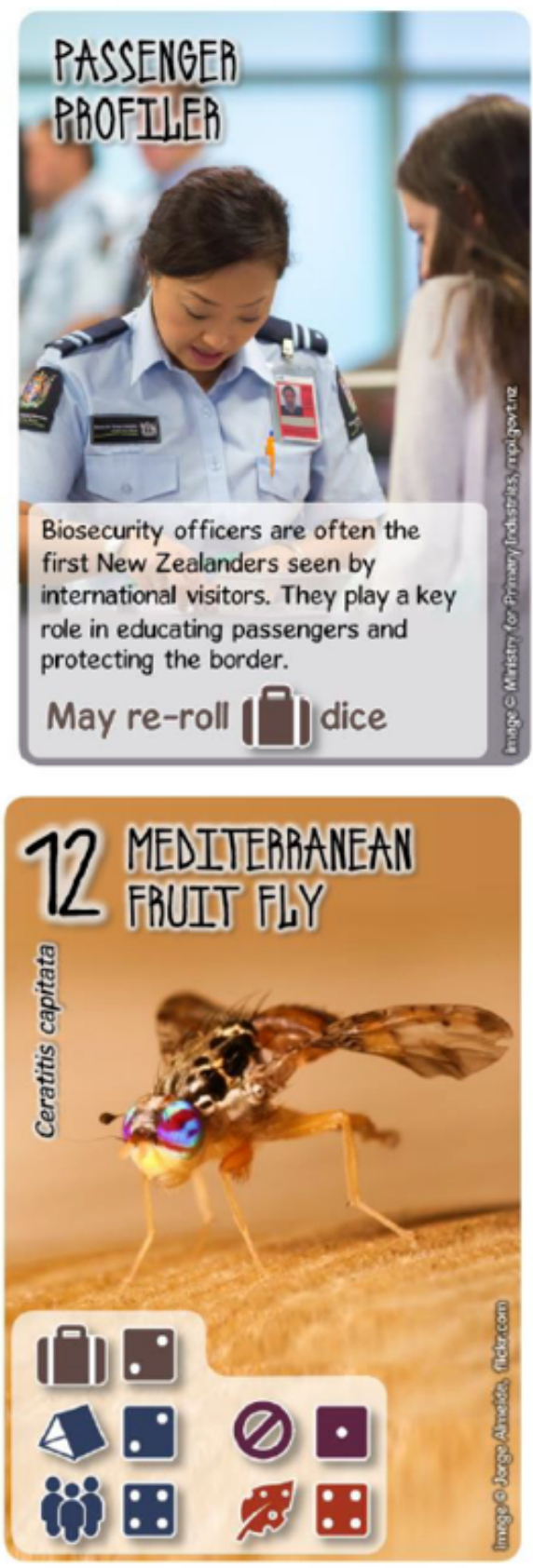

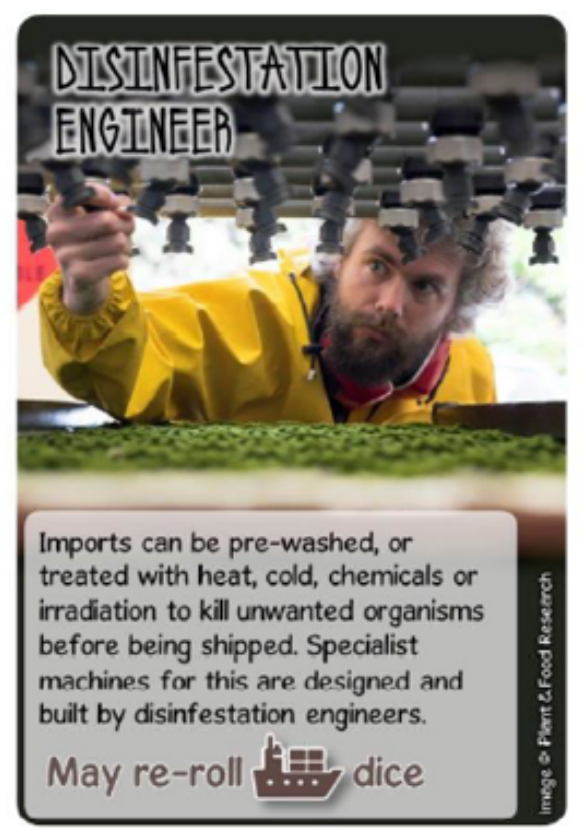

\section{円 ASIAN GYPSY MOTH}

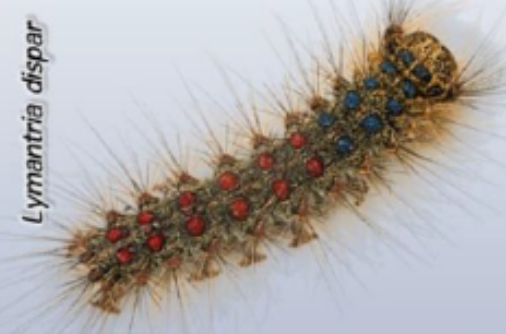

Gypsy moth caterpillars will eat many different kinds of trees, including NZ natives. In the USA it sometimes eats whole forests! Egg masses may be laid on ships and shipping containers, so $\mathrm{NZ}$ uses a trapping programme to detect it early and destroy it, as we did in Hamilton in 2003.
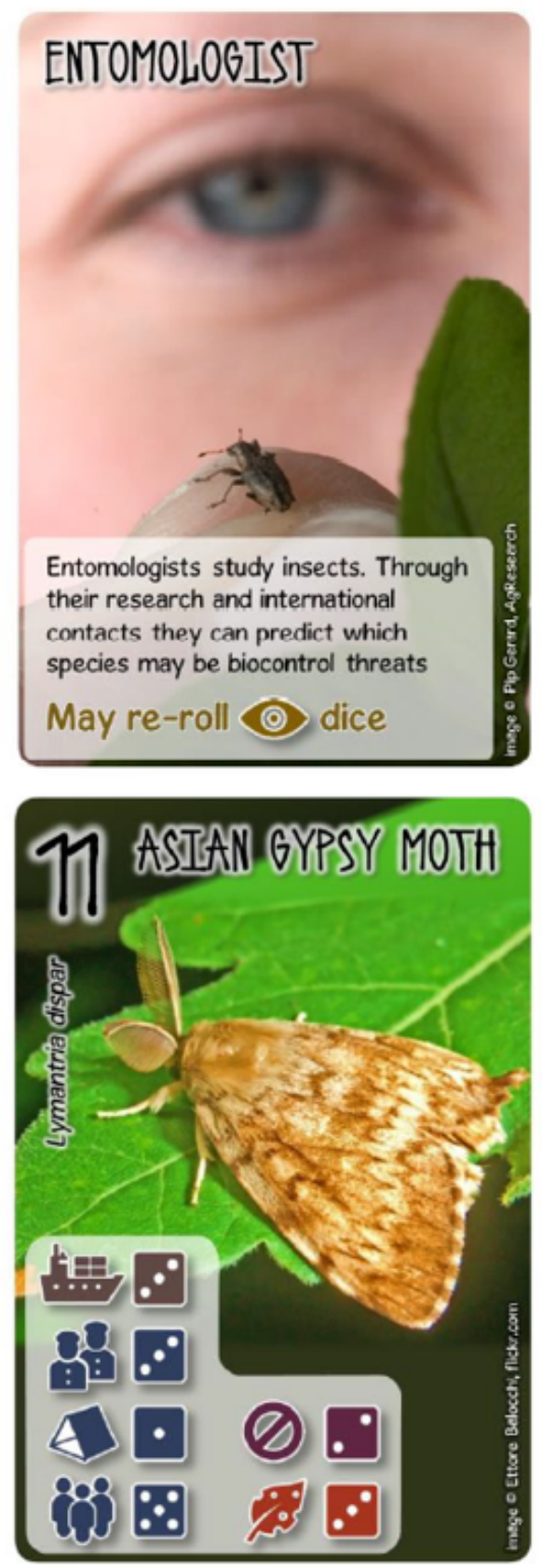

\section{Figure 2}

Role cards and pest threat cards from the 'Invasion Busters' biosecurity education kit board game

\begin{tabular}{|c|c|c|c|}
\hline $\begin{array}{l}\text { Please tick } \sqrt{\text { the box that best matches how you feel }} \\
\text { for each question. }\end{array}$ & Yes & $\underbrace{(\bullet \bullet)}_{\text {Maybe }}$ & No \\
\hline $\begin{array}{l}\text { I know that some insects can hurt other animals, plants } \\
\text { or people. }\end{array}$ & & & \\
\hline
\end{tabular}

Figure 3 
The 5-point smiley-face Likert scale used to assess children's answers to questions about biosecurity, with an example question

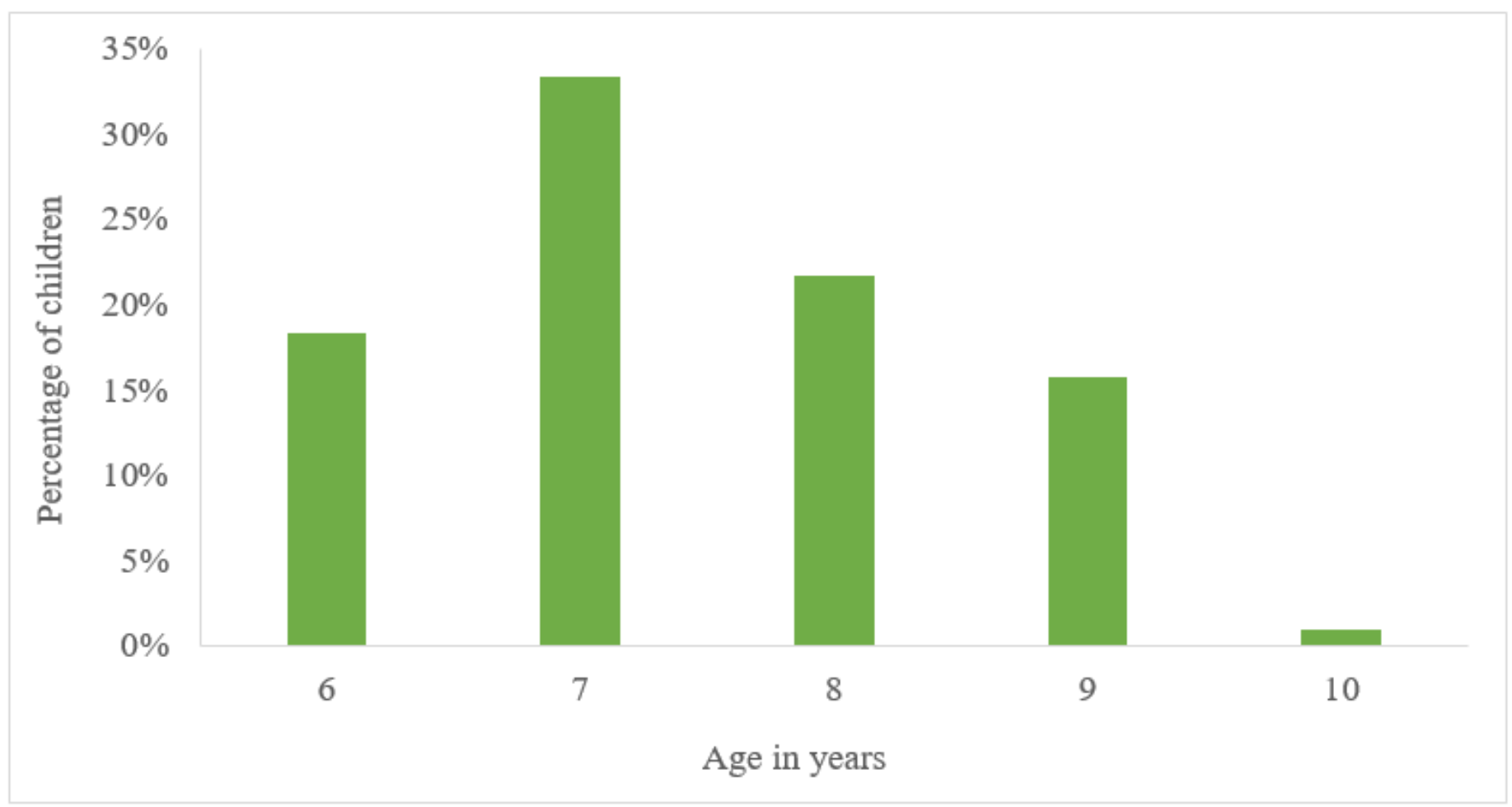

\section{Figure 4}

Age distribution of children in Study 2 


\section{I know what biosecurity is}

I know that some insects can hurt other animals, plants or people

It is important to stop new insects coming into New Zealand

I often look for insects around my home or school

I know which insects might hurt animals, plants or people in New Zealand

I know what to do if I see a bad insect

I would tell someone if I saw a bad insect

My family talk about stopping bad insects from hurting animals, plants or people

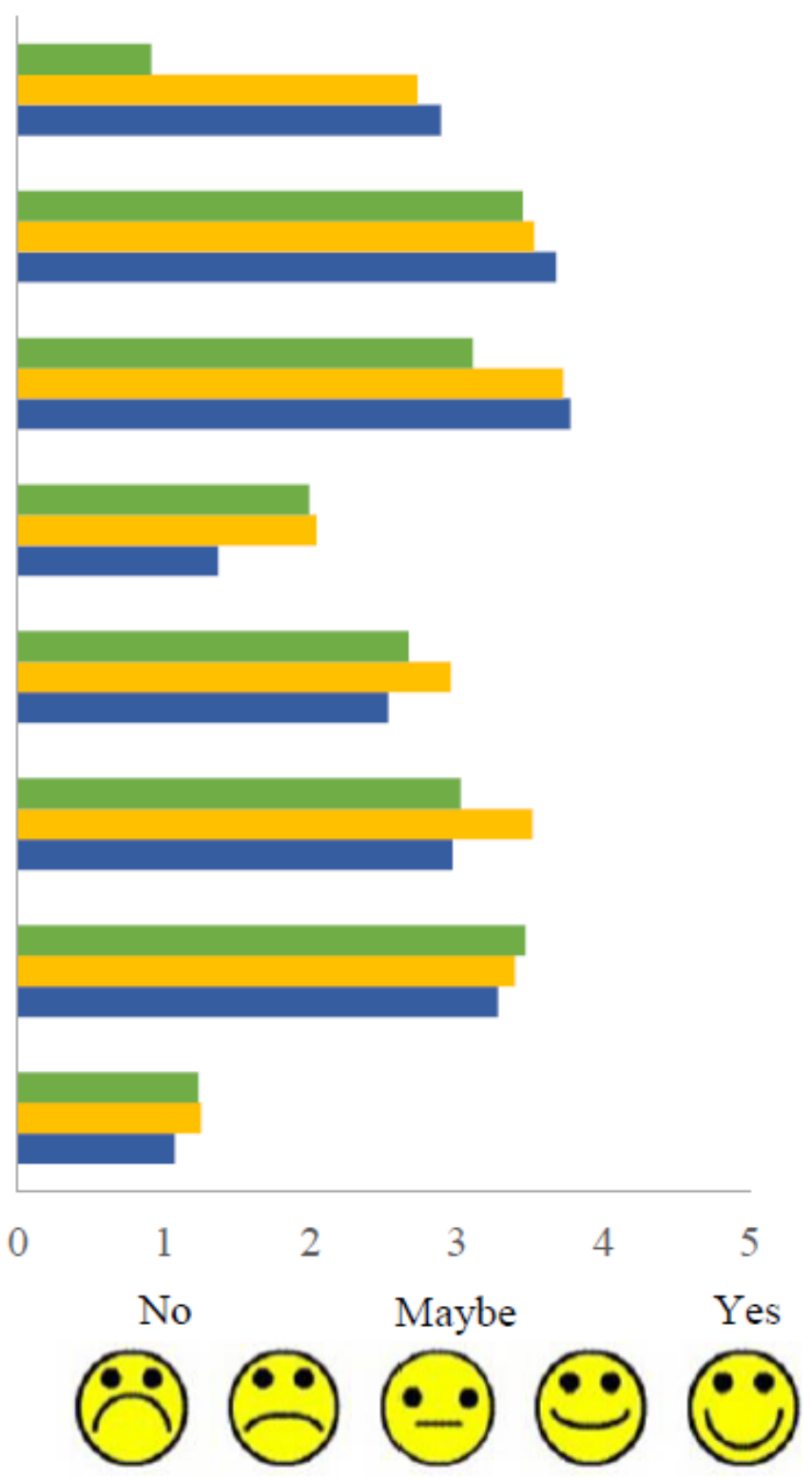

\section{Figure 5}

Children's predicted mean scores on smiley face Likert scale questions before, after and six months after using the biosecurity education kit 


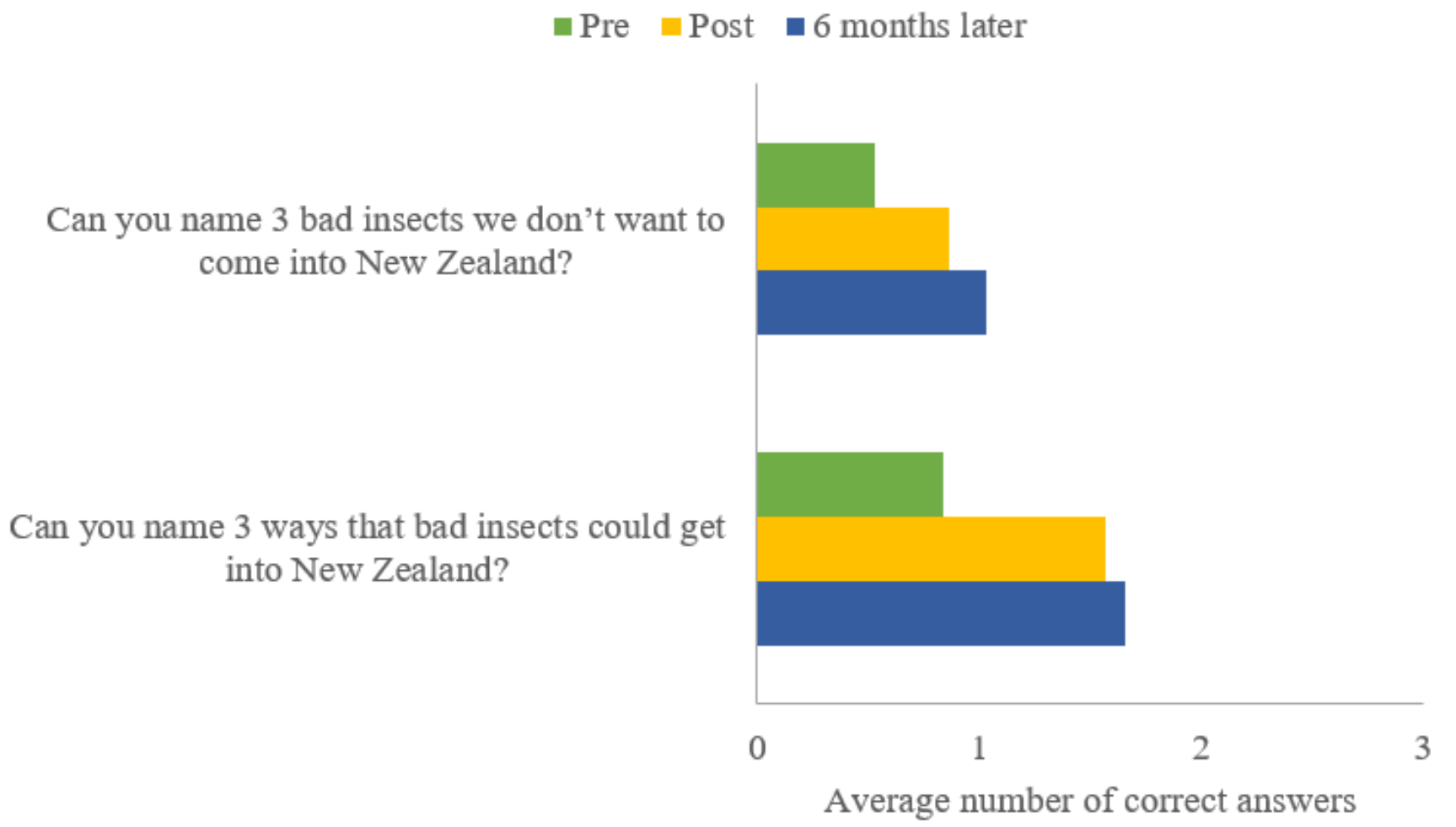

Figure 6

Children's average scores for correctly naming biosecurity threats and pathways, before, after and six months after using the biosecurity kit 


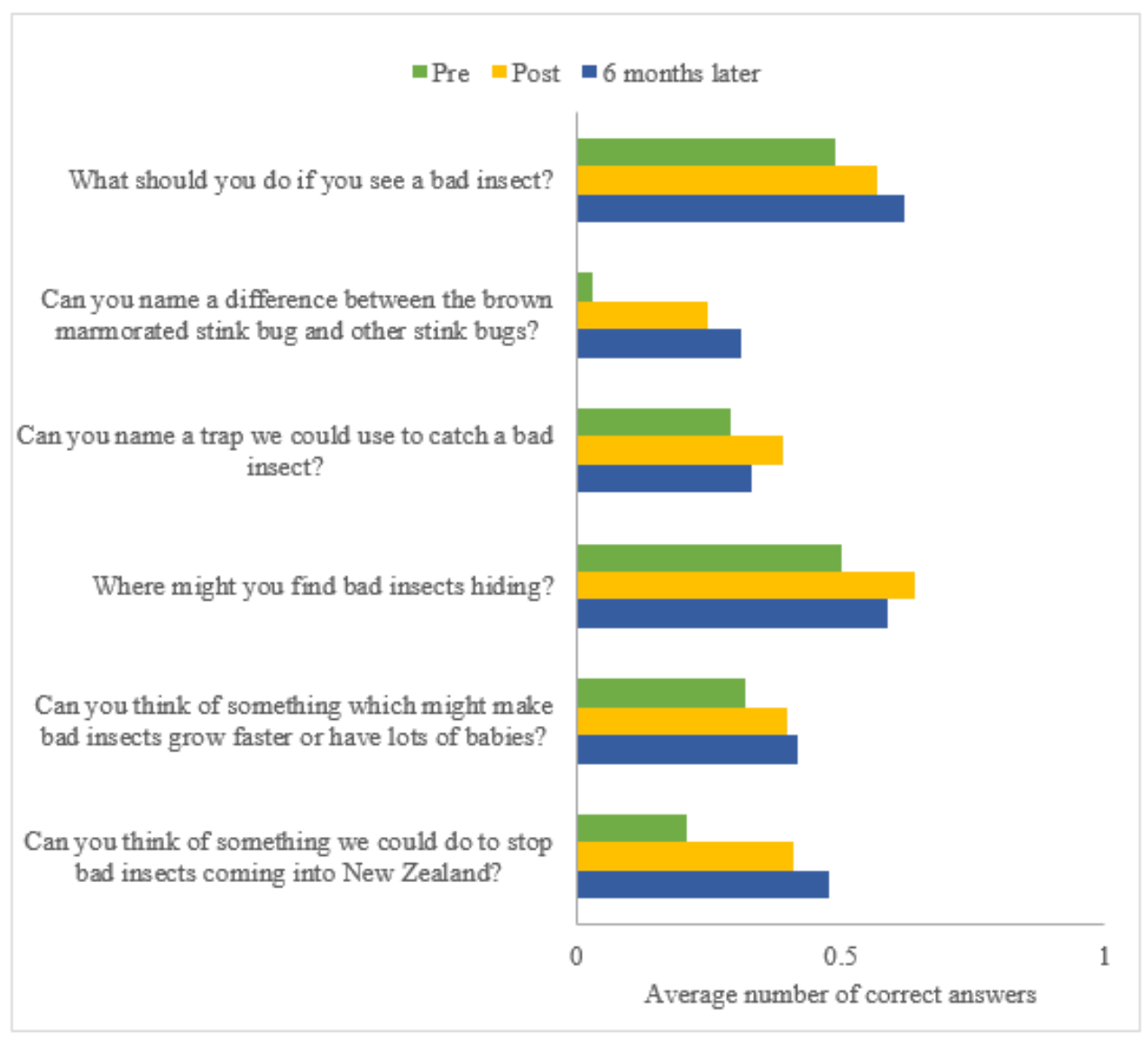

\section{Figure 7}

Children's average scores for a range of open-ended biosecurity questions, before, after and six months after using the biosecurity kit (where 0.5 was a partially correct answer) 